\title{
Serum Vitamin D Levels and Severity of Liver Dysfunction in Cirrhotic Patients
}

\author{
Kambiz Yazdanpanah', Farshad Sheykhesmeeili², Baran Parhizkar', Abbas Ghasemi ${ }^{*}$ \\ ${ }^{1}$ Associate Professor, Department of Hepatology and Gastroenterology, Towhid Hospital, University of Kurdistan, Head of De- \\ partment of Internal, University of Kurdistan, Kurdistan, Iran \\ ${ }^{2}$ Assistant Professor and Head of Department of Hepatology and Gastroenterology, Towhid Hospital, University of Kurdistan, \\ Kurdistan, Iran \\ ${ }^{3}$ Assistant Professor, Department of Hepatology and Gastroenterology, Towhid Hospital, University of Kurdistan, Kurdistan, Iran \\ ${ }^{4}$ Chief Resident of Internal Medicine, Department of Hepatology and Gastroenterology, Towhid Hospital, University of Kurdistan, \\ Kurdistan, Iran
}

Email: ^dr_ab_ghasemi@yahoo.com

How to cite this paper: Yazdanpanah, K., Sheykhesmeeili, F., Parhizkar, B. and Ghasemi, A. (2017) Serum Vitamin D Levels and Severity of Liver Dysfunction in Cirrhotic Patients. International Journal of Clinical Medicine, 8, 402-411.

https://doi.org/10.4236/ijcm.2017.86038

Received: January 4, 2017

Accepted: June 20, 2017

Published: June 23, 2017

Copyright $\odot 2017$ by authors and Scientific Research Publishing Inc. This work is licensed under the Creative Commons Attribution International License (CC BY 4.0).

http://creativecommons.org/licenses/by/4.0/

\begin{tabular}{|c|}
\hline (c) $\underset{\mathrm{EY}}{(1)}$ Open Acc \\
\hline
\end{tabular}

\begin{abstract}
Background and objective: Cirrhosis affects hundreds of millions of patients all around the world. Vitamin D deficiency is frequently observed in chronic hepatic disease. Vitamin D level may be an important survival marker in advanced liver cirrhosis. Material and Methods: The study is a sectional one of the descriptive-analytical type, where 90 of the patients with hepatic cirrhoses were selected with census sampling method. In all the cirrhotic patients, for diagnosis in clinical findings, the serological marker, autoantibodies were stable; biochemical endoscopy and imaging were the histological evidence and examinations and were then analyzed by SPSS version 22 software. Results: Based on the study, from the aspect of Child-Pugh classification, the highest vitamin D levels had the highest value in Child-Pugh class A with a frequency of 13 (43\%) in the form of insufficiency, and had the highest value in ChildPugh class B and C in the form of slight deficiency. Conclusion: It was specified based on the results obtained from the research that different vitamin $\mathrm{D}$ levels and liver failure severity have a significant relationship with each other $(\mathrm{p}<0.05)$ in patients suffering from hepatic cirrhosis, such that the serum vitamin $\mathrm{D}$ level decreases as liver failure severity increases.
\end{abstract}

\section{Keywords}

Cirrhosis, Vitamin D, Liver, Child-Pugh

\section{Introduction}

A chronic Hepatic disease, cirrhosis affects hundreds of millions of patients all around the world. Vitamin D deficiency is frequently observed in chronic he- 
patic disease. Vitamin D level may be an important survival marker in advanced liver cirrhosis [1]. The main source of the vitamin in humans is contact with the skin exposed to sunlight, where vitamin D hydroxylation occurs in the liver in the form of 25(OH)VIT D3 using enzymes like cytochrome P450 present in mitochondria and microsomes, and hydroxylation is in the form of $1.25(\mathrm{OH})$ VIT D3 in the kidney. Different factors are involved in vitamin D deficiency, one of which is hepatic 25-hydroxylation disorder. Vitamin D supplement level can best be measured by measuring 25(OH)VIT D3 levels [2]. Besides its role in calcium and phosphorus homeostasis, it plays an important role in body immune system adjustment in the form of antimicrobial peptide induction, innate immune response suppression, cytokine induction, and Thelper 2 [3].

In a series of studies conducted before, the relationship between the severity of some chronic hepatic diseases and vitamin D deficiency value has been specified. In Arteh J's study, vitamin D deficiency prevalence in 112 hepatic cirrhosis patients visiting a clinic was $92 \%$, at least around one third of whom suffer from intense deficiency $(\mathrm{p}<0.05)$ [4]. Caroline S's study demonstrated a significant relationship between vitamin $\mathrm{D}$ low level and mortality in chronic hepatic patients based on the severity of cirrhosis hepatic disease based on Child-Pugh classification $(\mathrm{p}<0.012)$. Vitamin $\mathrm{D}$ serum level was specified as an important mortality factor in this cohort study $(p=0.012)$ [5]. Therefore, in view of the high prevalence of hepatic cirrhosis and its mortality as well as the high prevalence of vitamin D deficiency in the public and its higher prevalence in patients with hepatic cirrhosis and the role vitamin D plays in osteoporosis, bone fracture and muscle strength decrease and inflammatory response disorder and malignity and even mortality as well as better response to treatment of some patients with hepatic cirrhosis, convinced us to consider the factors disturbing the above studies such as multifactorial causes of vitamin D deficiency and also consider as far as possible all causes of hepatic cirrhosis and specify the hepatic disease severity to obtain serum vitamin D level and hepatic cirrhosis severity so that vitamin D level range can be determined to some extent at any level of hepatic cirrhosis severity, and it can be determined through this study how much vitamin D deficiency there is at each hepatic disease severity if the disturbing factors are removed, so that the required supplements are prescribed with the recommended dosage based on hepatic disease severity, and with prescription of the dosages of vitamin $\mathrm{D}$ determined based on disease severity, effective steps are taken in increasing muscle strength and treating inflammatory response disorder and malignity and even mortality as well as better response to treatment of some patients with hepatic cirrhosis and preventing from complications.

\section{Objectives of the Study}

- Specification of the relationship between serum vitamin D level and hepatic cirrhosis severity in cirrhotic patients based on Child-Pugh classification.

- Specification of the relationship between serum vitamin D level and hepatic cirrhosis severity in cirrhotic patients based on MELD score. 
- Specification of the relationship between serum vitamin D and serum albumin levels in hepatic cirrhotic patients.

- Specification of the relationship between serum vitamin D and hepatic enzyme levels in hepatic cirrhotic patients.

- Specification of the relationship between serum vitamin D and Plt levels in hepatic cirrhotic patients.

- Specification of the relationship between serum vitamin D and GFR levels in hepatic cirrhotic patients.

- Specification of the relationship between serum vitamin D and serum PTH, calcium, and phosphorus levels in hepatic cirrhotic patients.

- Specification of the relationship between serum vitamin D level and age, gender, and BMI in hepatic cirrhotic patients.

- Specification of the relationship between serum vitamin D level and cirrhosis cause in hepatic cirrhotic patients.

- Specification of the relationship between serum vitamin D level and visiting season in hepatic cirrhotic patients.

\section{Material and Methods}

The study is a sectional one of the descriptive-analytical type and Information on ethics committee approval and informed consent. In this cirrhotic study, for diagnosis in clinical findings, the serological marker of Hepatitis B and C, Hepatitis $\mathrm{B}$ virus DNA, and Hepatitis $\mathrm{C}$ virus RNA measurement using polymerase chain reaction method, autoantibodies (anti-cell antibody, anti-smooth muscle antibody) were stable; biochemical (such as iron studies, ceruloplasmin, and copper urine), endoscopy, imaging (such as abdominal sonography) were the histological evidence and examinations (liver biopsy examination). Diagnosis of cirrhosis was based on liver biopsy or clinical evidence or deterministic biochemistry of liver failure and/or portal hypertension [6]. 90 of the hepatic cirrhotic patients visiting and hospitalized at Towhid Hospital, Sanandaj were selected using the sampling method, in 2015-2016. During data collection, the BMIs, ages, genders, and visiting seasons and whether their locations are urban or rural was specified for all of the patients. Diagnosis in clinical and laboratory findings and the serological marker of Hepatitis B and C, Hepatitis B virus DNA, and Hepatitis $C$ virus RNA measurement using polymerase chain reaction method, autoantibodies (anti-cell antibody, anti-smooth muscle antibody) biochemical (such as iron studies, ceruloplasmin, and copper urine), endoscopy and imaging were the histological evidence and examinations (liver biopsy examination). Diagnosis of cirrhosis was based on liver biopsy or clinical evidence or deterministic biochemistry of liver failure and/or portal hypertension. Blood sample was taken after one night $10-12$ hours fasting, and sent to the unit laboratory. CBC was performed by Cell Counter machine ( $\mathrm{K}^{\star} 21 \mathrm{Sysx}$ ), and ALT, AST, ALK, Ph, $\mathrm{Ca}, \mathrm{Cr}, \mathrm{P}, \mathrm{PTT}, \mathrm{T}, \mathrm{INR}$, and Alb, Bil T were performed by autoanalyzer machine and Japanese Prestige model biochemistry. Serum Ca Level was corrected with Alb density. PTH was measured by ELISA kit from American company Biomedical and 25(OH)VIT D3 by chemiluminescent kit from German company 
ROSH. The tests were performed using available commercial kits based on the instructions provided by the producing factory. Abdominal sonography (Hitachi EUB-405, machine equipped with 3.5 megahertz convex probe) was used for examination of the liver, spleen, ascites, and portal vein in all the patients by a radiology specialist. The patients were classified into three groups using ChildPugh: Class A (disease compensated well, scores 5 - 6) Class B (significant functional compromise, scores 7 - 9) Class C (disease decompensated, scores 10 - 15). MELD was measured.

In this research, using Chi Square statistical analyses for the categorical variables and Independent T-test for the continuous variables, Logistic Regression Test was used for specification of the predictive variables in occurrence of hepatic cirrhosis, Kolmogorov Test for investigation of the quantitative variable distribution type, variance analysis (ANOVA) for comparison of the variables between the groups of vitamin D, for Pearson correlation coefficients between vitamin D and Child-Pugh and the other variables in SPSS software version 22. The study was approved by the Ege University Ethical Committee. Written informed consent was obtained from patients who participated in this study.

\section{Results}

\section{Analytical Results}

The results of Chi Square statistical test did not demonstrate a significant relationship between Alkp, Alb, Plt, and Ca ( $\mathrm{p}>0.05$ ); but statistically significant relationships were observed between Child-Pugh classification, ALT, INR, AST, $\mathrm{Ph}, \mathrm{PTH}$, Season, Causes of disease, Location, and Gender $(\mathrm{p}<0.05)$ Table 1. The results on that basis, the highest vitamin D levels based on Child-Pugh had the highest value in insufficient form in Child class A with a frequency of 13 (43\%) and the highest value in mild deficiency form in Child class B and C Table 2. For ALT enzyme, it had the highest value in mild deficiency form with a frequency of $20(62 \%)$ for normal patients and $26(44 \%)$ for abnormal ones; for gender, it had the highest value in mild deficiency form with a frequency of 24 (43\%) for the men and 22 (62\%) for the women; for AST enzyme serum level, it had the highest value in mild deficiency form with a frequency of 28 (51\%) for normal patients and 18 (50\%) for abnormal ones; for $\mathrm{PH}$ value, it had the highest value in mild deficiency form with a frequency of 39 (51\%) for normal patients and 7 (50\%) for abnormal ones; for PTH hormone, it had the highest value in mild deficiency form with a frequency of 28 (45\%) for normal patients and 18 (64\%) for abnormal ones; for the patients' visiting seasons, it had the highest value in mild deficiency and insufficient value form with a frequency of 5 (35\%) for Spring, in mild deficiency form with a frequency of 22 (57\%) for Summer, in mild deficiency form with a frequency of $12(66 \%)$ for Fall, and in moderate deficiency form with a frequency of $8(40 \%)$ for Winter; for cause of the disease Table 3. The results shows that the highest values respectively concern Hepatitis B with a frequency of 21 (53\%) in mild deficiency form, Hepatitis C with a frequency of 4 (44\%) in moderate deficiency form, Autoimmune $\mathrm{H}$ with a frequency 
Table 1. Relationship between the variables being studied and vitamin D levels.

\begin{tabular}{|c|c|c|c|c|c|c|c|c|}
\hline Variable & Dimensions & $\begin{array}{c}\text { Severe } \\
\text { deficiency }\end{array}$ & $\begin{array}{l}\text { Moderate } \\
\text { deficiency }\end{array}$ & $\begin{array}{c}\text { Mild } \\
\text { deficiency }\end{array}$ & Insufficient & Sufficient & $x^{2}$ & (p. value) \\
\hline \multirow{3}{*}{ Child-Pugh } & Child A & 0 & $3(10 \%)$ & $13(43 \%)$ & $11(36 \%)$ & $3(10 \%)$ & \multirow{3}{*}{20} & \multirow{3}{*}{0.007} \\
\hline & Child B & $1(2 \%)$ & $12(27 \%)$ & $24(55 \%)$ & $5(11 \%)$ & $1(2 \%)$ & & \\
\hline & Child C & 0 & $4(47 \%)$ & $9(52 \%)$ & 0 & 0 & & \\
\hline \multirow{2}{*}{ Alkp } & Normal (64-06) & $1(2 \%)$ & $13(28 \%)$ & $19(41 \%)$ & $11(23 \%)$ & $2(4 \%)$ & \multirow{2}{*}{4} & \multirow{2}{*}{0.05} \\
\hline & $306<$ Abnormal $<64$ & 0 & $10(22 \%)$ & $27(61 \%)$ & $5(11 \%)$ & $2(4 \%)$ & & \\
\hline \multirow{2}{*}{ ALT } & Normal $\geq 31$ & 0 & $4(12 \%)$ & $20(62 \%)$ & $6(18 \%)$ & $2(6 \%)$ & \multirow{2}{*}{5} & \multirow{2}{*}{0.001} \\
\hline & Abnormal $\leq 31$ & $1(1 \%)$ & $19(32 \%)$ & $26(44 \%)$ & $10(17 \%)$ & $2(3 \%)$ & & \\
\hline \multirow{2}{*}{ Gender } & Male & $1(1 \%)$ & $14(25 \%)$ & $24(43 \%)$ & $13(23 \%)$ & $3(5 \%)$ & \multirow{2}{*}{5} & \multirow{2}{*}{0.001} \\
\hline & Female & 0 & $9(25 \%)$ & $22(62 \%)$ & $3(8 \%)$ & $1(2 \%)$ & & \\
\hline \multirow{2}{*}{ AST } & Normal $\geq 31$ & 0 & $14(25 \%)$ & $28(51 \%)$ & $10(18 \%)$ & $2(3 \%)$ & \multirow{2}{*}{1} & \multirow{2}{*}{0.001} \\
\hline & Abnormal $\leq 31$ & $1(2 \%)$ & $9(25 \%)$ & $18(50 \%)$ & $6(16 \%)$ & $2(5 \%)$ & & \\
\hline \multirow{2}{*}{ Alb } & Normal (3.5 - 5.5) & 0 & $6(14 \%)$ & $22(52 \%)$ & $12(28 \%)$ & $2(4 \%)$ & \multirow{2}{*}{9} & \multirow{2}{*}{0.041} \\
\hline & Abnormal $<3.5$ & $1(2.1 \%)$ & 17 (35\%) & $24(50 \%)$ & $4(8 \%)$ & $2(4 \%)$ & & \\
\hline \multirow{2}{*}{ Plt } & Normal $(150,000-450,000)$ & 0 & $4(40 \%)$ & $4(40 \%)$ & 0 & $2(20 \%)$ & \multirow{2}{*}{9} & \multirow{2}{*}{0.051} \\
\hline & $450,000<$ Abnormal $<150,000$ & $1(1 \%)$ & $19(23 \%)$ & $42(52 \%)$ & $16(20 \%)$ & $2(2 \%)$ & & \\
\hline \multirow{3}{*}{$\mathrm{Ca}$} & Hypocalcaemia & $1(2 \%)$ & $16(47 \%)$ & $15(44 \%)$ & $2(5 \%)$ & 0 & \multirow{3}{*}{19} & \multirow{3}{*}{0.012} \\
\hline & Normocalcaemia & 0 & $7(13 \%)$ & $29(54 \%)$ & $13(24 \%)$ & $4(7 \%)$ & & \\
\hline & Hypercalcaemia & 0 & 0 & $2(66 \%)$ & $1(33 \%)$ & 0 & & \\
\hline \multirow{2}{*}{$\mathrm{Ph}$} & Normal $(2.6-4.5)$ & $1(1 \%)$ & $20(26 \%)$ & $39(51 \%)$ & $14(18 \%)$ & $2(2 \%)$ & & \\
\hline & $4.5<$ Abnormal $<2.6$ & 0 & $3(21 \%)$ & $7(50 \%)$ & $2(14 \%)$ & $2(14 \%)$ & 7.20 & 0.001 \\
\hline DTH & Normal $(1.3-6.8)$ & 0 & $17(27 \%)$ & $28(45 \%)$ & $13(20 \%)$ & $4(6 \%)$ & 6 & 0001 \\
\hline 121 & $6.8<$ Abnormal $<1.3$ & $1(3 \%)$ & $6(21 \%)$ & $18(64 \%)$ & $3(10 \%)$ & 0 & 政 & \\
\hline & Spring & 0 & $3(21 \%)$ & $5(35 \%)$ & $5(35 \%)$ & $1(7 \%)$ & & \\
\hline Cononn & Summer & 0 & $9(23 \%)$ & $22(57 \%)$ & $4(10 \%)$ & $3(7 \%)$ & 15 & 0001 \\
\hline Jedsont & Fall & 0 & $3(16 \%)$ & $12(66 \%)$ & $3(16 \%)$ & 0 & 10 & 0.001 \\
\hline & Winter & $1(5 \%)$ & $8(40 \%)$ & $7(35 \%)$ & $4(20 \%)$ & 0 & & \\
\hline & Hepatitis B & 0 & $8(20 \%)$ & $21(53 \%)$ & $8(20 \%)$ & $2(5 \%)$ & & \\
\hline & Hepatitis C & 0 & $4(44 \%)$ & $3(33 \%)$ & $2(22 \%)$ & 0 & & \\
\hline & Autoimmune & 0 & $2(33 \%)$ & $3(50 \%)$ & 0 & $1(16 \%)$ & & \\
\hline & Cryptogenic & $1(5 \%)$ & $3(15 \%)$ & $10(52 \%)$ & $4(12.1 \%)$ & $1(5 \%)$ & & \\
\hline Cause & Thrombosis & 0 & $2(33 \%)$ & $2(33 \%)$ & $2(33 \%)$ & 0 & 19 & 0.001 \\
\hline & Cardiac & 0 & $3(37 \%)$ & $5(62 \%)$ & 0 & 0 & & \\
\hline & PSC & 0 & $1(100 \%)$ & 0 & 0 & 0 & & \\
\hline & Alcoholic & 0 & 0 & $1(100 \%)$ & 0 & 0 & & \\
\hline & Wilson & 0 & 0 & $1(100 \%)$ & 0 & 0 & & \\
\hline I & Urban & $1(1 \%)$ & $18(32 \%)$ & $32(57 \%)$ & $3(5 \%)$ & $2(3 \%)$ & 17 & $000 ?$ \\
\hline Locationi & Rural & 0 & $5(14 \%)$ & $14(41 \%)$ & $13(38 \%)$ & $2(5 \%)$ & 17 & 0.002 \\
\hline NDD & Normal (1 - 1.4) & 0 & $4(14 \%)$ & $11(39 \%)$ & $9(32 \%)$ & $4(14 \%)$ & & 0000 \\
\hline $1 N K$ & $1.4<$ Abnormal $<1$ & $1(1 \%)$ & $19(30 \%)$ & $35(56 \%)$ & $7(11 \%)$ & 0 & 17 & 0.002 \\
\hline
\end{tabular}


Table 2. Relationship between hepatic cirrhosis severities based on Child-Pugh and vitamin D serum level.

\begin{tabular}{ccc}
\hline Child-Pugh & Patient frequency & Vitamin D level mean \\
\hline A & 30 & 52.56 \\
B & 43 & 35.68 \\
C & 17 & 24.73 \\
& 90 & 39.4 \\
\hline
\end{tabular}

Table 3. Relationship between patients' visiting seasons and vitamin D serum level mean.

\begin{tabular}{ccc}
\hline Visiting season & Number of patients & Vitamin D level mean \\
\hline Spring & 13 & 48.46 \\
Summer & 38 & 40.32 \\
Fall & 19 & 38.62 \\
Winter & 20 & 31.79 \\
\hline
\end{tabular}

of $3(50 \%)$ in mild deficiency form, Cryptogenic with a frequency of $10(52 \%)$ in mild deficiency form, Thrombosis with a frequency of 2 (33\%) in insufficient, mild deficiency, and moderate deficiency equal forms, Cardiac with a frequency of 5 (62\%) in mild deficiency form, and PSC and Wilson with frequencies of 1 $(100 \%)$ in moderate deficiency form; for location, it was in mild deficiency form with a frequency of $32(57 \%)$ for the patients from urban locations and in mild deficiency form with a frequency of $14(41 \%)$ for those from rural locations; as for INR, it was in mild deficiency form with a frequency of 11 (39\%) for normal patients and in mild deficiency form with a frequency of 35 (56\%) for abnormal patients Table 4 and Table 5.

Based on the results obtained from Anova test, since the observed significance level is less than 0.05 at 95 percent confidence level, there is statistically significant difference between age, BMI, and MELD, BilT, and GFR criteria and different vitamin $D$ levels ( $p<0.05)$; on that basis, the highest vitamin $D$ value has the lowest value for the patients' ages with 66 and 57 average years of age, the highest value for BMI with $23 \mathrm{~kg} / \mathrm{m}^{2}$ in average and the lowest with $17 \mathrm{~kg} / \mathrm{m}^{2}$, the highest value for MELD score with an average of 17 and the lowest with 16, the highest value for BILT with $4 \mathrm{mg} / \mathrm{dl}$ in average and the lowest with $2 \mathrm{mg} / \mathrm{dl}$, and the highest value for GFR with an average of $59 \mathrm{ml} / \mathrm{min}$ and the lowest value with $40 \mathrm{ml} / \mathrm{min}$.

Based on the results obtained from logistic regression, it was observed that the Wald test statistic is 2 for Alb, and with p-value $=0.86>0.05$, the factor is not effective on the patients' hepatic cirrhosis severity in this study, and the variable is not considered as a prognostic factor, which can be caused by albumin reception during paracentesis of abdominal ascites liquid. But the other variables being studied (Gender, Alkp, ALT, AST, Plt, Ph, PTH, and INR) are effective on the patients' hepatic cirrhosis severity, and are considered as prognostic factors in the patients' hepatic cirrhosis severity. Lack of in Patients with testing, the limitations and shortcomings of the study. 
Table 4. Vitamin D serum level mean based on the patients' genders.

\begin{tabular}{cc}
\hline Gender & Vitamin D serum level mean \\
\hline Male & 55 \\
Female & 35 \\
\hline
\end{tabular}

Table 5. Relationship between cause of cirrhosis and vitamin D serum level mean.

\begin{tabular}{ccc}
\hline Cause of cirrhosis & Number of patients & Vitamin D serum level mean \\
\hline Hepatitis B & 39 & 40.1 \\
Hepatitis C & 9 & 33.43 \\
Autoimmune H & 6 & 51.20 \\
Cryptogenic & 19 & 41.37 \\
Thrombosis & 6 & 38.75 \\
Cardiac & 8 & 30.42 \\
PSC & 1 & 22.90 \\
Alcoholic & 1 & 42.90 \\
Wilson & 1 & 35.60 \\
& 90 & 39.24 \\
\hline
\end{tabular}

\section{Discussion}

The results showed that a significant relationship was observed between ChildPugh classification and different vitamin D levels $(\mathrm{p}<0.05)$; on that basis, there was a trend of lower vitamin $\mathrm{D}$ level with cirrhosis increase severity. The results of the research are in accordance with some studies [5] [6] [7] and are in contradiction to some other studies [8] [9]. A significant relationship was observed between MELD score and different vitamin D levels $(\mathrm{p}<0.05)$. Actually, it can be stated that with hepatic functioning disorder in chronic hepatic disease and in view of the role the liver plays in producing active vitamin $\mathrm{D}$ (25-hydroxilation), there is serum vitamin $\mathrm{D}$ deficiency. The results show that a significant relationship was observed between gender and different vitamin D levels $(\mathrm{p}<0.05)$ Table 4. The cross-sectional study demonstrated that there was an interaction between vitamin D density and gender in relationship [10]. A significant relationship was observed between different vitamin D levels and serum calcium value, on which basis most of the patients with vitamin D deficiency had normal calcium and phosphate serum levels which are in line with Arash Miroliaee's results [6]; this can explained by reabsorption of minerals from bones. A significant relationship was observed between $\mathrm{Ph}$ and different vitamin $\mathrm{D}$ levels $(\mathrm{p}<$ 0.05), where the highest vitamin D levels had a frequency of 39 (51\%) for normal patients and 7 (50\%) for abnormal ones in mild deficiency form. There was also a significant relationship between PTH and different vitamin D levels $(\mathrm{p}<0.05)$, where the highest vitamin D levels had a frequency of 28 (45\%) for normal patients and 18 (64\%) for abnormal ones in mild deficiency form. The results show that a significant relationship was observed between visiting season and different vitamin D levels $(p<0.05)$, where the highest vitamin D level averages con- 
cerned Spring, Summer, Fall, and Winter, respectively, with a frequency of 5 (35\%) in mild deficiency and insufficient value form in Spring, a frequency of 22 (57\%) in mild deficiency form in Summer, a frequency of $12(66 \%)$ in mild deficiency form in Fall, and a frequency of 8 (40\%) in moderate deficiency form in Winter Table 3. A significant relationship was observed between cause of disease and different vitamin D levels $(\mathrm{p}<0.05)$, where the highest vitamin $\mathrm{D}$ level averages were in Autoimmune Hepatitis, Alcoholic, and Cryptogenic, respectively, and the lowest level was in PSC. This can explain by cholestasis effect in VIT D level for PSC but low number of PSC and Wilson patients was interference in results. A significant relationship was observed between location and different vitamin D levels ( $\mathrm{p}<0.05 ; \mathrm{r}: 74 \%$ ), where the highest vitamin D levels were in mild deficiency form with a frequency of 32 (57\%) for the patients from urban locations and in mild deficiency form with a frequency of 14 (41\%) for those from rural locations, which can be explained in terms of the fact that an important vitamin D production resource is exposure to sunlight. A significant relationship was observed between ALT enzyme and different vitamin D levels $(\mathrm{p}<0.05)$, where the highest vitamin D levels had a frequency of $20(62 \%)$ for normal patients and 26 (44\%) for abnormal ones in mild deficiency form. There was also a significant relationship between AST enzyme and different vitamin D levels ( $\mathrm{p}<0.05)$, where the highest vitamin D levels had a frequency of $28(51 \%)$ for normal patients and 18 (50\%) for abnormal ones in mild deficiency form. A significant relationship was observed between BilT and different vitamin D levels $(\mathrm{p}<0.05)$, where the highest vitamin $\mathrm{D}$ value was with an average of $4 \mathrm{mg} / \mathrm{dl}$, and the lowest was with $2 \mathrm{mg} / \mathrm{dl}$. There was a significant relationship between INR and different vitamin $\mathrm{D}$ levels $(\mathrm{p}<0.05)$, where the highest vitamin $\mathrm{D}$ levels were in mild deficiency form with a frequency of 11 (39\%) for normal patients and in mild deficiency form with a frequency of 35 (56\%) for abnormal ones. It can be stated that with hepatic functioning disorder in chronic hepatic disease and in view of the role the liver plays in producing active vitamin D (25-hydroxilation). A significant relationship was observed between age and different vitamin $D$ levels $(\mathrm{p}<0.05)$, where the highest vitamin $\mathrm{D}$ value was for an average age of 66 years, and the lowest value was for 57 years that was unlike expectation. This can explain by not equal number of male and female patients in our study. This A significant relationship was observed between GFR and different vitamin D levels ( $p<0.05$ ), where the highest vitamin $D$ value was for an average of 59 , and 40 had the lowest value. ESRD was excluded in our study. Furthermore, the results obtained from logistic regression demonstrated that Alb is not effective on the patients' hepatic cirrhosis severity, and the variable is not considered as a prognostic factor. But the other variables being studied (Gender, ALKP, ALT, AST, Plt, Ph, PTH, and INR) are effective on the patients' hepatic cirrhosis severity, and are considered as prognostic factors in the patients' hepatic cirrhosis severity.

Based on the results obtained from the research, it became clear that there is a significant relationship between different vitamin D levels and hepatic failure 
severity in patients suffering from hepatic cirrhosis. On that basis, as hepatic failure severity increases, serum vitamin $\mathrm{D}$ level decrease. In addition to its role in calcium metabolism, vitamin $\mathrm{D}$ derivatives may be involved in cell proliferation, differentiation, and immunomodulation. Vitamin D inhibits certain types of matrix metalloproteinases (MMP) [11]. Consequently, vitamin D deficiency has been associated with increased circulating MMP2.9, a situation that can be corrected with vitamin D supplementation [12]. Other effects of vitamin D include suppression of proliferation of fibroblasts and increased collagen production [13]. Vitamin D supplementation may have antifibrotic effects in patients [14]. Then, vitamin D levels should be monitoring and deficient patients should be treated with vitamin D supplementation [15]. Some studies demonstrated an association between vitamin $\mathrm{D}$ status and mortality amongst which liver diseases as a cause of death were included [16] [17].

\section{Limitations and Suggestions for Future Studies}

The limitation of this study concerned with the people who were examined as statistical population. It is suggested that the research be comparatively conducted in other hospitals on patients suffering from hepatic cirrhosis and determination required supplements are prescribed with the recommended dosage based on hepatic disease severity.

\section{References}

[1] Feldman, M., Friedman, L.S. and Lawrence, B.J. (2010) Sleisenger and Fordtran's Gastrointestinal and Liver Disease. 10th Edition, Saunders, Elsevier Science, 1554 p.

[2] Melmed, S., Polonsky, K.S., Larsen, P.R. and Kronenberg, H.M. (2011) Williams Textbook of Endocrinology. 13th Edition, Saunders, Elsevier Science.

[3] Longo, D., Fauci, A., Kasper, D., Hauser, S., Jamson, J. and Loscalzo, J. (2012) Harrison's Principles of Internal Medicine. Textbook Edition, Saunders, Elsevier Science, $2592 \mathrm{p}$.

[4] Arteh, J., Narra, S. and Nair, S. (2010) Prevalence of Vitamin D Deficiency in Chronic Liver Disease. Digestive Diseases and Sciences, 55, 2624-2628. https://doi.org/10.1007/s10620-009-1069-9

[5] Stokes, C., Krawczyk, M., Reichel, C., Lammert, F. and Grünhage, F. (2014) Vitamin D Deficiency Is Associated with Mortality in Patients with Advanced Liver Cirrhosis. European Journal of Clinical Investigation, 44, 176-183. https://doi.org/10.1111/eci.12205

[6] Miroliaee, A., Nasiri-Toosi, M., Khalilzadeh, O., Esteghamati, A., Abdollahi, A. and Mazloumi, M. (2010) Disturbances of Parathyroid Hormone-Vitamin D Axis in Non-Cholestatic Chronic Liver Disease. Hepatology International, 4, 634-640. https://doi.org/10.1007/s12072-010-9194-2

[7] Malham, M., Jorgrnsen, S.P., Ott, P., Angnholt, J., Vildtrup, H., Borre, M. and Dehlerup, J.F. (2011) Vitamin D Deficiency in Cirrhosis Relates to Liver Dysfunction Rather than Etiology. World Journal of Gastroenterology, 17, 922-925. https://doi.org/10.3748/wjg.v17.i7.922

[8] Chen, C., Wang, S.S., Jeng, F.S. and Lee, S.D. (1996) Metabolic Bone Disease of Liver Cirrhosis: Is It Parallel to the Clinical Severity of Cirrhosis? Journal of Gastroenterology and Hepatology, 11, 417-421. 
https://doi.org/10.1111/j.1440-1746.1996.tb00284.x

[9] Monegal, A., Navasa, M., Guanabens, N., Peris, P., Pons, F., Martinez de Osaba, M.J., Rimola, A., Rodés, J. and Muñoz-Gómez, J. (1997) Osteoporosis and Bone Mineral Metabolism Disorders in Cirrhotic Patients Referred for Orthotopic Liver Transplantation. Calcified Tissue International, 60, 148-154. https://doi.org/10.1007/s002239900205

[10] Menkes, C. (2013) Epidemiology and Etiology of Osteomalacia. https://www.uptodate.com/contents/epidemiology-and-etiology-of-osteomalacia

[11] Koli, K. and Keski-Oja, J. (2000) 1alpha,25-Dihydroxyvitamin D3 and Its Analogues Down-Regulate Cell Invasion-Associated Proteases in Cultured Malignant Cells. Cell Growth \& Differentiation, 11, 221-229.

[12] Timms, P., Mannan, N., Hitman, G.A., Noonan, K., Mills, P.G., SyndercombeCourt, D., Aganna, E., Price, C.P. and Boucher, B.J. (2002) Circulating MMP9, Vitamin D and Variation in the TIMP-1 Response with VDR Genotype: Mechanisms for Inflammatory Damage in Chronic Disorders? QJM, 95, 787-796. https://doi.org/10.1093/qjmed/95.12.787

[13] Dobak, J., Grzybowski, J., Liu, F.T., Landon, B. and Dobke, M. (1994) 1,25-Dihydroxyvitamin $\mathrm{D}_{3}$ Increases Collagen Production in Dermal Fibroblasts. Journal of Dermatological Science, 8, 18-24. https://doi.org/10.1016/0923-1811(94)90316-6

[14] Rahman, A. and Branch, A.D. (2013) Vitamin D for Your Patients with Chronic Hepatitis C? Journal of Hepatology, 51, 184-189.

https://doi.org/10.1016/j.jhep.2012.07.026

[15] Abu-Mouch, S., Fireman, Z., Jarchovsky, J., Zeina, A.R. and Assy, N. (2011) Vitamin D Supplementation Improves Sustained Virologic Response in Chronic Hepatitis C (Genotype 1)-Naive Patients. World Journal of Gastroenterology, 17, 51845190. https://doi.org/10.3748/wjg.v17.i47.5184

[16] Skaaby, T., Husemoen, L.L., Pisinger, C., Jorgensen, T., Thuesen, B.H., Fenger, M. and Linneberg, A. (2012) Vitamin D Status and Cause-Specific Mortality: A General Population Study. PLoS ONE, 7, e52423. https://doi.org/10.1371/journal.pone.0052423

[17] Putz-Bankuti, C., Pilz, S., Stojakovic, T., Scharnagl, H., Pieber, T.R., Trauner, M., Obermayer-Pietsch, B. and Stauber, R.E. (2012) Association of 25-Hydroxyvitamin D Levels with Liver Dysfunction and Mortality in Chronic Liver Disease. Liver International, 32, 845-851. https://doi.org/10.1111/j.1478-3231.2011.02735.x

Submit or recommend next manuscript to SCIRP and we will provide best service for you:

Accepting pre-submission inquiries through Email, Facebook, LinkedIn, Twitter, etc. A wide selection of journals (inclusive of 9 subjects, more than 200 journals)

Providing 24-hour high-quality service

User-friendly online submission system

Fair and swift peer-review system

Efficient typesetting and proofreading procedure

Display of the result of downloads and visits, as well as the number of cited articles

Maximum dissemination of your research work

Submit your manuscript at: http://papersubmission.scirp.org/

Or contact ijcm@scirp.org 